Received: January 10, 2018

Revision received: March 21, 2018

\title{
Optimization of Continuing Education of Marine Human Resources in China Based on System Stability
}

\author{
Yujing Chang ${ }^{1}$ \\ Xin Zhang ${ }^{2}$ \\ Hebei Normal University of Science \& \\ Technology \\ Hebei Maritime Safety Administration of \\ People's Republic of China
}

\begin{abstract}
In view of the shortage of marine talents and the slow progress of academic backbones, this paper analyzed in details the status quo of marine human resources and deficiencies in the existing marine education in China, and then proposed a plan for continuing education optimization based on the marine system stability in terms of the teaching mode, cultivation mechanism, and incentives. This plan was put forward as a reference for the development of marine talent education in China so as to optimize the allocation of marine human resources and vigorously advance the marine industry.
\end{abstract}

\section{Keywords}

Marine Resources, System Stability • Optimization of Continuing Education • Allocation of Human Resources

\footnotetext{
${ }^{1}$ Correspondence to: Yujing Chang (MA), College of Business Administration, Hebei Normal University of Science \& Technology, Qinhuangdao 066004, China. Email: yjc9980@126.com;

2 Hebei Maritime Safety Administration of People's Republic of China, Qinhuangdao 066001, China. Email: olivebing@126.com.
}

Citation: Chang, Y. J., \& Zhang, X. (2018). Optimization of Continuing Education of Marine Human Resources in China Based on System Stability. Educational Sciences: Theory \& Practice, 18(5), 2403-2409. http://dx.doi.org/10.12738/estp.2018.5.139 
The marine industry, the main component of the marine economy and one of the important emerging industries in China, has been increasingly important in China's overall economic and social development layout as the marine mining technology continues advancing (Wang \& Lv, 2006). The research (Chen, 2017) pointed out that the special technological requirements of the marine industry makes its development highly dependent on the advanced technology, while the human resources as the master of science and technology play a vital role in the marine industry development. Therefore, the improvement of the development capability of talents can effectively promote the competence cultivation of marine human resources, and play an important role in continuously improving the competitiveness of China in the marine economy market and promoting the development of China's marine economy. The marine economy system is an organic economy composed of various marine industries that depend on and restrict each other. In recent years, the academia has paid increasingly more attention to the researches on the marine system stability (Wang \& Huang, 2010). Compared with the terrestrial economy system, the marine economy system sees more prominent fluctuations, while its stability is manifested in the interference resistance and the pursuit of new stability after interference. The research (Wang, Lin \& Prokhorov, 2017) argued that this capability includes not only the resistance and resilience of the system under actual interference, but also the early warning and stability maintenance potential of the system for possible interference impact.

The human resources of marine technology (Chen \& Zhang, 2000) feature high technical and innovation requirements and frequent talent mobility. Since very early, China has valued the cultivation of marine talents. The continuing education of marine human resources in marine-related enterprises is necessary for the establishment of a maritime power and a strong marine economy and the development of marine human resources in various coastal cities. Colleges and universities should be taken as the main front for the promotion of marine human resources continuing education by expanding channels, improving the continuing education system, and strengthening cooperation and exchanges with other industries to cultivate crosssectional composite talents. Additionally, professional and technical personnel should have their rights and interests of continuing education safeguarded by improving the continuing education system to continuously enhance the professionalism and technical level and serve innovation-driven development strategy. Moreover, as the development of marine resources is a practice-based job, college graduates are usually short of practices and experience under the current theoretical education model, which makes the continuing education at work highly significant.

\section{Status Quo and Challenges of Marine Human Resources in China}

\section{Weak Awareness of Marine Education}

In China, the traditional culture values farming. Under the influence of farming thoughts, people have insufficient understanding of the ocean, and are greatly affected by the "agriculture-first and ocean-last" traditional consciousness, which leads to a certain gap of modern ocean concept between China and developed countries. In our national education, little marine knowledge is imparted in primary and secondary 
schools, leading to relatively shallow awareness of maritime rights and territory of students. In terms of educational resources, China also has certain shortcomings in the education of human resources, mainly reflected in insufficient investment in the marine educational resources. In the Beijing-Tianjin-Hebei region, Yangtze River Delta and Pearl River Delta, citizens show low level of marine knowledge with a lack of basics training. For example, before 2000, Ocean University of China was the only university in China named with ocean (Gu, Wu \& Dong, 2010). As of 2010, there were only less than ten marine professional colleges and universities in China. These institutions in the exploratory stage, due to slow start and lack of human resources, mostly deliver low-level education, except a few universities with abundant accumulations such as Ocean University of China (Gordts, Muthuramu, Geest \& Bart, 2010). Take Zhoushan City as an example. At the end of 2015, there were 2,500 professionals with a master's degree or above and 12,375 with a bachelor's degree among a total of over 300,000 marine employees in Zhoushan City, indicating a low proportion of high-level. The following is a table of the composition of marine related employees in China in 2016.

Table 1

Composition of Nationwide Marine Employees (2016)

\begin{tabular}{lccc}
\hline Marine industry & Employment(k) & Practitioner(k) & ratio \\
\hline total & 44350 & 4501 & $10.1 \%$ \\
fishery industry & 13354 & 2793 & $20.3 \%$ \\
Oil and gas & 7503 & 452 & $6.4 \%$ \\
Marine ore sand & 2202 & 787 & $35.2 \%$ \\
Marine chemical & 10051 & 926 & $9.1 \%$ \\
Marine organism & 825 & 138 & $14.6 \%$ \\
Marine ships & 11209 & 801 & $7.5 \%$ \\
\hline
\end{tabular}

\section{Unreasonable Structure and Imperfect Incentive Mechanism}

Since the founding of the People's Republic of China, China's marine science and technology has made great progress through arduous efforts. As of 2003, there are 159 large-scale marine research institutions and more than 20,000 marine technical professionals, which basically constitutes a research team with marine development capability covering all disciplines (Wang, 2003). The distribution of marine research institutions in major provinces of China is as follows:

Table 2

Distribution of Marine Research Institutions

\begin{tabular}{lcc}
\hline Province & research institute & Ratio \\
\hline Guangxi & 12 & $7 \%$ \\
Guangdong & 28 & $17 \%$ \\
Jiangsu & 39 & $24 \%$ \\
Zhejiang & 46 & $28 \%$ \\
Fujian & 34 & $21 \%$ \\
\hline
\end{tabular}

The survey (Liu, Wang, Ling, Zu \& Qin, 2018) showed that the existing laborers in the marine economy are about 5.4 million, mainly concentrated in coastal cities such as Jiangsu and Zhejiang. However, less than $1 \%$ of them are professionals, far behind the advanced marine countries such as Japan. The research (Zhang, Han, Yang, Han \& Gao, 2017) demonstrated that the illiteracy rate of marine practitioners in China is around 
$15 \%$, and the average educational level is the junior diploma. The cultivation of marine talents in China also sees the following problems. 1) The human resources are located unevenly. The marine talents are mainly concentrated in coastal first- and second-tier cities such as Shanghai, Guangzhou, Xiamen, Shenzhen, etc., but few in other coastal cities. 2) The marine human resources are excessively centered. Most of the marine scientific research teams in China work in junior colleges. Meanwhile, funds and personnel issues lead to certain marine talent resources waste. 3) The knowledge structure of marine human resources is poor. Colleges and universities in China impart relatively simple knowledge structure in marine professional education, and the textbooks lag behind marine frontier researches, with a lack of popular research topic teaching such as marine exploitation based on system stability. The faculty also fail to update their knowledge to the latest. All the above results in the serious lack of marine talents. Therefore, greater challenged are posed in the competition of marine talents in modern society.

In social and economic life, a reasonable incentive mechanism is an important way to ensure the vitality of a professional discipline. A flexible and reasonable incentive system can enhance the enthusiasm of practitioners and help them to maximize their subjective initiative and potential. However, in China's marine human resource management, the irrational incentive mechanism restricts the development of talents to a certain extent. It is mainly reflected in the following aspects. 1) The distribution of benefits is under the planned economy, and the current distribution system is not absolutely market-oriented, which cannot fully reflect the true value of talents. In the actual practice, distribution is not based on labor but on the seniority. 3) The incentive policy has not been implemented. Although many localities have introduced incentive measures for marine talents, the lack of policy continuity and other reasons have made it difficult to realize the funds finally, compromising the effect of incentives.

\section{Stability of the Marine System}

The system stability refers to the ability of a system to be interfered in a steady state and then return to a stable state after the interference disappears. This is a system cybernetic concept. Researches on the stability of marine systems at home and abroad mainly focus on the marine ecosystem, the marine economic system, and the marine power system.

\section{Time Domain Characteristics}

The stability of China's marine economic system changes over time. According to the data, it can be seen that the stability median of the marine system witnessed relatively low growth rate from 2002 to 2017 . Generally speaking, the stability of the marine system is positively correlated to the economic growth, mining, pollution and other events. For example, Dalian Xingang Port oil pipeline explosion in 2010 resulted in the pollution of 50-square-kilometer sea surface by crude oil, which significantly affected the quality of local seawater and brought fluctuations in the aquaculture and shipping industries. With the development of more marine oil and gas resources, blowout accidents, ship collision, and leakage incidents will increase to negatively impact the marine economy system. At the same time, despite various measures taken by China to 
continuously improve the stability of the marine system, the marine stability has not been improved greatly but just maintained at a stable level in recent years, due to over-exploitation driven by higher demands for marine products.

\section{Geographical Characteristics}

First of all, China's marine economic system is characterized by the distribution model of overall dispersion and partial connectivity. The stability gap between different coastal areas is obvious. For example, the stability of Guangdong Province is significantly higher than that of Guangxi Province. According to the survey 6, the stability of China's marine system is divided into three categories, namely (1) high stability, mainly represented by Shanghai, Shandong, and Guangdong that take rich marine protection measures and focus on sustainable development to rank themselves among the first nationwide, (2) moderate stability, including Fujian, Tianjin, and Jiangsu whose relatively frequent fluctuations are mainly affected by man-made mining, (3) low stability, involving Guangxi, Hainan, and Liaoning that depend heavily on the ocean in the context of economic underdevelopment and undergo excessive and unscientific marine mining. In general, the more developed the marine economy in a region, the higher the stability index of its marine economic system. On the contrary, the less advanced the marine economy in a region, the lower the stability index of its marine economic system. The first and second-tier cities with faster marine economic development and larger scale have stronger stability, while the cities with lower economic levels in Hebei and Guangxi have relatively low stability. From the above analysis, it can be found that the stability of the marine economy system is positively correlated with the level of local economic development.

\section{Optimization Plan for Human Resources Continuing Education}

Based on the above analysis of the stability of China's marine system and the education of marine talents, the optimization plan for marine human resources education was put forward in view of the small coverage of marine human resources education and the old-fashioned knowledge structure, which mainly includes the following aspects.

\section{Customize Continuing Education Plans According to Different Regions}

The major coastal provinces differ from and municipalities directly under the Central Government in the marine development. The colleges and universities tend to impart general knowledge that cannot be connected to local conditions. Therefore, the continuing education program should be customized in line with the region where the practitioners work. For example, continuing education in Tianjin should focus on the coordination of economic growth efficiency and ecological environment protection, and promote the stable development of Tianjin's marine economy driven by the expertise of marine human resources. In Hebei province, as its marine economic system stability heavily depends on the marine-related scientific and technological personnel and the structure and status quo of the marine economy, the continuing education should focus on the industrial 
structure and improvement of economic growth modes. In Liaoning province, the stability of the marine economy system is mainly affected by over-exploitation and utilization of resources and insufficient technical support, which means the professional cultivation should prefer emerging marine strategic industries as the main direction of future development. In Shanghai, the marine economy features outstanding outward-looking nature and large scale, so the industrial structure of employees should be further optimized to supplement scarce talents. Jiangsu province should increase the proportion of science and technology in promoting the development of marine economy and enhance the cultivation of high-quality talents in the marine industry. In Zhejiang and Fujian provinces with poor infrastructure construction and insufficient natural resources should strengthen the continuing education of infrastructure construction talents, and enhance the environmental protection and effective use of new energy.

\section{Strengthen University-Enterprise Cooperation and Integrate Educational Resources}

In the labor-intensive industries such as marine tourism, shipbuilding, and port logistics, enterprises are demanding in the professional skills and innovative ability of talents. Therefore, it is necessary to promote indepth cooperation between educational institutions and enterprises. 1) The continuing education should follow the practicability-oriented rule and enhance the cooperation between enterprises and educational institutions to take advantages of each other. Universities and colleges should develop targeted textbooks in line with production and service needs and keep pace with the development of enterprises to actively promote the reform of the talent training model, while enterprises should further learn the most advanced research topics from universities and colleges. 2) The incentive model should be transformed to encourage innovation and introduce marine scientific research results into class. To cultivate innovative marine high-level talents, it is necessary for marine colleges and universities to recruit faculty with independent thinking and innovation ability. They should establish and improve the incentive system for mutual promotion of scientific research and teaching to guide teachers to bring marine scientific and technological innovations into class and optimize the continuing education of professional courses in marine majors. In recent years, universities, such as Ocean University of China, Shanghai Maritime University, and Dalian Maritime University, have seen significant results on continuing education innovation through the teaching forms innovation of marine majors and continuous integration of in-class teaching, scientific research training, professional skills training, experimental internships, and comprehensive quality exercises. 3) The "double-skilled" faculty should be cultivated. Universities' teachers mainly stay in the campus and seldom connect with enterprises, but the continuing education of human resources must conform to the demands of enterprises. Therefore, teachers need to keep up with the latest requirements of enterprises and be dispatched to enterprises for temporary practice. Through understanding the production methods and job responsibilities of enterprises, they can generate higher continuing education quality. 


\section{Conclusion}

The marine industry is labor-intensive and knowledge-intensive. This paper deeply analyzed the characteristics of China's marine system stability and the continuing education of marine talents. In view of the current shortage of marine professionals and the slow growth of academic backbones, this paper proposed a continuing education optimization plan based on the stability of the marine system, and gave optimization suggestions from the aspects of teaching mode, training mechanism and incentives, which is to provide reference for the development of marine talent education in China, optimize the structure of marine human resources, and promote the further development of the marine industry.

\section{References}

Chen, G., \& Zhang, S. K. (2000). Review of Human Reliability Assessment (HRA) in ocean engineering. Ocean Engineering, 18(4), 6-12.

Chen, X. L. (2017). Assessment and prediction of china's ocean strategy resource safety based on DSR model-take the south china sea oil security for example. World Regional Studies, 26(3), 46-58.

Gordts, Muthuramu, S., Geest, I. D., \& Bart. (2010). Key lab of submarine geosciences and prospecting techniques (ministry of education), ocean university of China. Marine Geology \& Quaternary Geology, 71-72. http://doi.org/10.1002/9781119009795.indsp

Gu, X., Wu, Z. P, \& Dong, X. W. (2010). Strategy of flourishing ocean through technology and teaching and g.higher education institution of china ocean engineering. Journal of Northeast Agricultural University, 6, $50-53$.

Liu, N., Wang, H., Ling, T. J., Zu, Z. Q., \& Qin, Y. H. (2018). Development of global ocean general circulation numerical forecasting system in china. Marine Science Bulletin, 2, 139-148.

Wang, L., \& Huang, C. B. (2010). Dynamic stability analysis of a grid-connected solar-concentrated ocean thermal energy conversion system. IEEE Transactions on Sustainable Energy, 1(1), 10-18. http://doi.org/10.1109/tste.2010.2046189

Wang, L., Lin, C. Y., \& Prokhorov, A. V. (2017). Stability analysis of a microgrid system with a hybrid offshore wind and ocean energy farm fed to a power grid through an HVDC link. Industry Applications Society Meeting 1-9. http://doi.org/10.1109/TIA.2017.2787126

Wang, M. (2003). Strategic thinking on development of ocean economy in china in the 21st century. (11), 2732.

Wang, M., \& Lv, B. (2006). The causes and strategies of loss of china's ocean resource assets. Resources Science, 2006(5), 102-107.

Zhang, H., Han, C., Yang, J., Han, L., \& Gao, W. (2017). Current sharing status and the utilization prospect of ocean data in china. Ocean Development \& Management, 3, 3-11. 